\title{
ANALISANDO INDICADORES SOBRE A RECEPÇÃO DE LITERATURA EM UM AMBIENTE DE MÚLTIPLOS SUPORTES
}

André Carlos Moraes

\begin{abstract}
RESUMO: A partir de observações de autores como Marshall McLuhan e Sven Birkerts, realizouse levantamento com estudantes universitários a fim de observar suas formas de contato com obras literárias e verificar eventual substituição da leitura por mídias audiovisuais. Os resultados apontaram que em lugar de oposição ou concorrência pôde ser notada uma complementaridade entre os suportes de conteúdo. $\mathrm{O}$ indicador primário adotado na pesquisa foi a lista de leituras obrigatórias para a prova de literatura do vestibular da Universidade Federal do Rio Grande do Sul. Vários estudantes empregaram múltiplas formas de apropriação do conteúdo das obras, e foram mesmo observadas estratégias de estudo que conscientemente alternaram mídias a fim de maximizar os resultados.
\end{abstract}

PALAVRAS-CHAVE: Leitura. Livro eletrônico. Futuro do livro. Suportes múltiplos.

Este artigo busca reunir observações teóricas e cotejá-las com dados empíricos obtidos a partir de uma pesquisa que lidou com as inter-relações entre literatura, meios eletrônicos, impressos, oralidade e suportes audiovisuais. Busca-se, aqui, uma perspectiva multidisciplinar. A primeira seção procura oferecer um delineamento de problema a partir de preocupações encontradas em autores das disciplinas de história, literatura e comunicação. Na segunda seção, são apresentados resultados de um levantamento realizado com estudantes, trazendo insights sobre seu relacionamento com a literatura e a forma como realizam a integração, às vezes em estado de fluxo contínuo, entre livros, filmes e meio digital. As considerações finais apontam perspectivas nas quais seja possível enquadrar pesquisas futuras na área, com vistas a desenvolvimentos teóricos que contemplem a questão mais ampla da literatura em um ambiente de múltiplos suportes.

\section{Identificando preocupações}

Em um livro sugestivamente chamado "A arte perdida da leitura", o norte-

\footnotetext{
Doutorando pelo Programa de Pós-Graduação em Comunicação e Informação da Universidade Federal do Rio Grande do Sul (PPGCOM UFRGS), Porto Alegre, Brasil. E-mail para contato: andrecmoraes@uol.com.br.
} 
americano David Ulin conta um diálogo que teve com seu filho, que estava tendo dificuldades em cumprir uma leitura escolar. Ele começa com uma declaração feita pelo jovem:

\begin{abstract}
"É por isso que não se lê mais. Nenhum dos meus amigos gosta. Ninguém mais quer fazer isso."

Ele sustentou meu olhar por um longo momento, como se me desafiando a apresentar um contra-argumento. Pensei por um instante em responder, mas não havia nada a dizer. De certa forma, este era o conflito primal, meu filho declarando sua independência, dizendo-me que a leitura não importava em uma sala cheia de livros, meus livros, milhares deles nas prateleiras. [...] A literatura está morta, Noah me disse, por isso que não se lê mais. E, de fato, eu via agora com a força de revelação, eu não podia dizer que ele estava errado. ${ }^{1}$ (ULIN, 2009, p.8-9, Grifos do autor)
\end{abstract}

Ulin eventualmente conclui que os livros e a literatura estão em oposição ao conjunto representado pelas outras formas de comunicação. "Ler, afinal, é um ato de resistência em um panorama de distração, uma questão de engajamento em uma sociedade que nada mais quer para nós do que o desengajamento."2 (ULIN, 2009, p.150) Historicamente, esta linha de análise é identificada com o ensaísta canadense Marshall McLuhan, autor do postulado de que "todos os efeitos da tecnologia tipográfica encontram-se agora em forte oposição à tecnologia eletrônica" (MCLUHAN, 1972, p. 311).

Independente das convicções pessoais dos autores citados ou da validade de seus argumentos, identifica-se uma preocupação continuada a respeito da relação entre os livros e o contexto cultural multimídia. Este conflito seria sentido especialmente entre as novas gerações de leitores ainda não formados, como argumenta o crítico norte-americano Sven Birkerts:

A absorção da cultura impressa pelas tecnologias eletrônicas continuou a grande velocidade, e confrontamos as consequências em toda parte. Para começar, jornais estão em crise, suas circulações despencando à medida que velhos leitores desertam para fontes on-line de áreas específicas (parte do fenômeno de nicho) e jovens leitores deixam de aderir como novos consumidores. Estes leitores potenciais já têm novas preferências condicionadas e novos reflexos para lidar com informação - con-

\footnotetext{
${ }^{1}$ Original em inglês. Tradução do autor deste artigo.

${ }^{2}$ Original em inglês. Tradução do autor deste artigo.
} 
dicionamento que, não surpreendentemente, afeta também a leitura de livros. $^{3}$ (BIRKERTS, 2006, p. 238)

Birkerts elabora mais abertamente do que Ulin uma preocupação com a pressão exercida pelas novas tecnologias sobre as novas gerações, o que estaria se traduzindo na formação de uma quantidade menor de leitores. Sua análise aponta, inclusive, o que seria um declínio mais amplo da cultura impressa, notado tanto pela queda de leitores de jornais quanto pelas mudanças no público leitor de livros.

Essa preocupação de alguns autores tem versões mais radicais. De forma hiperbólica, o trecho abaixo do brasileiro Juremir Machado da Silva faz um diagnóstico sombrio:

Tudo isso ficará para trás. Manobra efêmera de um tempo de transição. Haverá autores no futuro, noutras artes, mas não "escritores". As palavras continuarão gerando arte e dinheiro, mas não como escrita. [...] Já se pode sentir o perfume do passado em cada página, mesmo virtual, que se vira. Vale repetir: não é só o livro que desaparecerá, é a escrita. Não é a escrita em material impresso que sairá de cena, mas a escrita em qualquer suporte. (SILVA, 2012, p.127)

Justamente o exagero deste tipo de previsão justifica o interesse de pesquisa endereçado pelo presente artigo. Para que se evite incorrer na tentação de fazer profecias extrapolando juízos teóricos, convém que se transforme as preocupações em problemas de investigação apreensíveis dentro do processo científico. Uma estratégia metodológica para isso é a observação empírica. Este é o procedimento de pesquisa aconselhado pelo britânico John B. Thompson, justamente, ao se dedicar à análise do panorama do livro no contexto das mídias eletrônicas em seu livro Books in the Digital Age. Ele escreve:

Podemos abordar estes temas diferentemente enfatizando que tecnologias devem sempre ser contextualizadas - isto é, elas devem sempre ser analisadas em relação aos contextos sociais específicos nos quais elas são desenvolvidas e usadas, e daí em relação ao que os usuários realmente fazem com estas tecnologias $[\ldots]^{4}$ (THOMPSON, 2008, p. 317)

\footnotetext{
${ }^{3}$ Original em inglês. Tradução do autor deste artigo.

${ }^{4}$ Original em inglês. Tradução do autor deste artigo.
} 
A pesquisa cujos dados são utilizados neste artigo, justamente, partiu dessa premissa metodológica para abordar as preocupações expressas mais acima. A seção a seguir apresenta resultados de um levantamento que procurou observar, em um corpus específico e delimitado, a forma como se articulam tecnologias, literatura e hábitos culturais de uma amostra de jovens.

\section{Dados de observação}

A seguir são apresentados resultados da pesquisa realizada para a dissertação de mestrado "Entre livros e e-books: a apropriação de textos eletrônicos por estudantes ingressados na Universidade Federal do Rio Grande do Sul em 2011", defendida pelo autor do presente artigo no Programa de Pós-Graduação em Comunicação e Informação da Universidade Federal do Rio Grande do Sul (PPGCOM UFRGS) em 2012. Realizado em um programa de Comunicação, o trabalho se dedicava a comparar suportes de leitura. A presente análise utiliza o mesmo data set mas extrapola o âmbito da dissertação, ao efetuar a leitura dos dados em um contexto multidisciplinar.

É necessário esclarecer o planejamento da pesquisa original. Buscava-se observar comparativamente como uma amostra de público jovem efetuava leituras nos diferentes suportes. Para isso, optou-se como indicador primário pela lista de leituras obrigatórias do vestibular da UFRGS. Há uma seleção de 12 livros de literatura brasileira que os candidatos inscritos na prova recebem. O levantamento realizado buscou observar, junto a uma amostra de alunos aprovados, quantos livros haviam lido e em quais suportes. Buscava-se, sobretudo, observar a incidência das preferências por livro impresso e eletrônico. A pesquisa, entretanto, ofereceu grande riqueza de observações, objeto do presente artigo.

Foram distribuídos questionários fechados a 263 estudantes de primeiro ano da UFRGS, todos aprovados no vestibular 2011. Havia campos perguntando quais títulos da lista haviam sido lidos na íntegra e quais de forma parcial, assim como solicitando que fossem especificadas as formas de apropriação. Outras questões 
não ligadas ao indicador principal eram perguntas abertas sobre preferências genéricas de leitura. $O$ corpus foi composto por alunos de 9 cursos de graduação da UFRGS, escolhidos a partir da maior densidade de candidatos por vaga no vestibular nas 9 Grandes Áreas da Capes. A composição da amostra é detalhada na Tabela 1. Metodologicamente, é preciso esclarecer que o corpus deve ser entendido em termos qualitativos. Estatisticamente não é possível extrapolar os resultados, embora seja possível analisar relações numéricas dentro do grupo. Mas salienta-se que os dados não têm pretensão totalizante. Não representam a totalidade dos alunos da universidade, nem dos calouros daquele ano ou sequer a íntegra das turmas pesquisadas. Trata-se de indicativos.

\begin{tabular}{|ccccc|}
\hline curso & densidade & vagas no curso & amostra & percentual \\
\hline Medicina & 45,32 & 140 & 32 & $22,86 \%$ \\
\hline Direito & 18,9 & 70 & 37 & $52,86 \%$ \\
\hline Psicologia & 17,45 & 40 & 21 & $52,50 \%$ \\
\hline Publicidade & 14,7 & 50 & 29 & $58,00 \%$ \\
\hline Veterinária & 11 & 88 & 37 & $42,05 \%$ \\
\hline Engenharia Civil & 9,56 & 150 & 26 & $17,33 \%$ \\
\hline Computação & 7,55 & 100 & 29 & $29,00 \%$ \\
\hline Biologia & 6,75 & 100 & 26 & $26,00 \%$ \\
\hline Letras & 3,37 & 215 & 26 & $12,09 \%$ \\
\hline Total da amostra: 263 respondentes \\
\hline
\end{tabular}

Tabela 1: Composição da amostra de estudantes da pesquisa.

As leituras obrigatórias do vestibular estão na Tabela 2, precedidas de um código alfabético atribuído com fins de tabulação.

\begin{tabular}{|ll|}
\hline A - Basílio da Gama - O Uraguai & \\
\hline B - José de Alencar - Lucíola & G - Cyro Martins - Porteira Fechada \\
\hline C - Machado de Assis - Memórias Póstumas de Brás Cubas & H - Guimarães Rosa - Manuelzão e Miguilim \\
\hline D - Contos de Machado de Assis & I - Dias Gomes - O Pagador de Promessas \\
\hline E - Eça de Queirós - O Primo Basílio & J - Rubem Fonseca - Feliz Ano Novo \\
\hline F - Manuel Bandeira - Estrela da Vida Inteira & K - Cristóvão Tezza - O Filho Eterno \\
\hline
\end{tabular}

Tabela 2: Lista de leituras obrigatórias do vestibular 2011 da UFRGS. 
Uma última informação relevante sobre a composição da amostra está no Gráfico 1. Trata-se da distribuição etária dos respondentes.

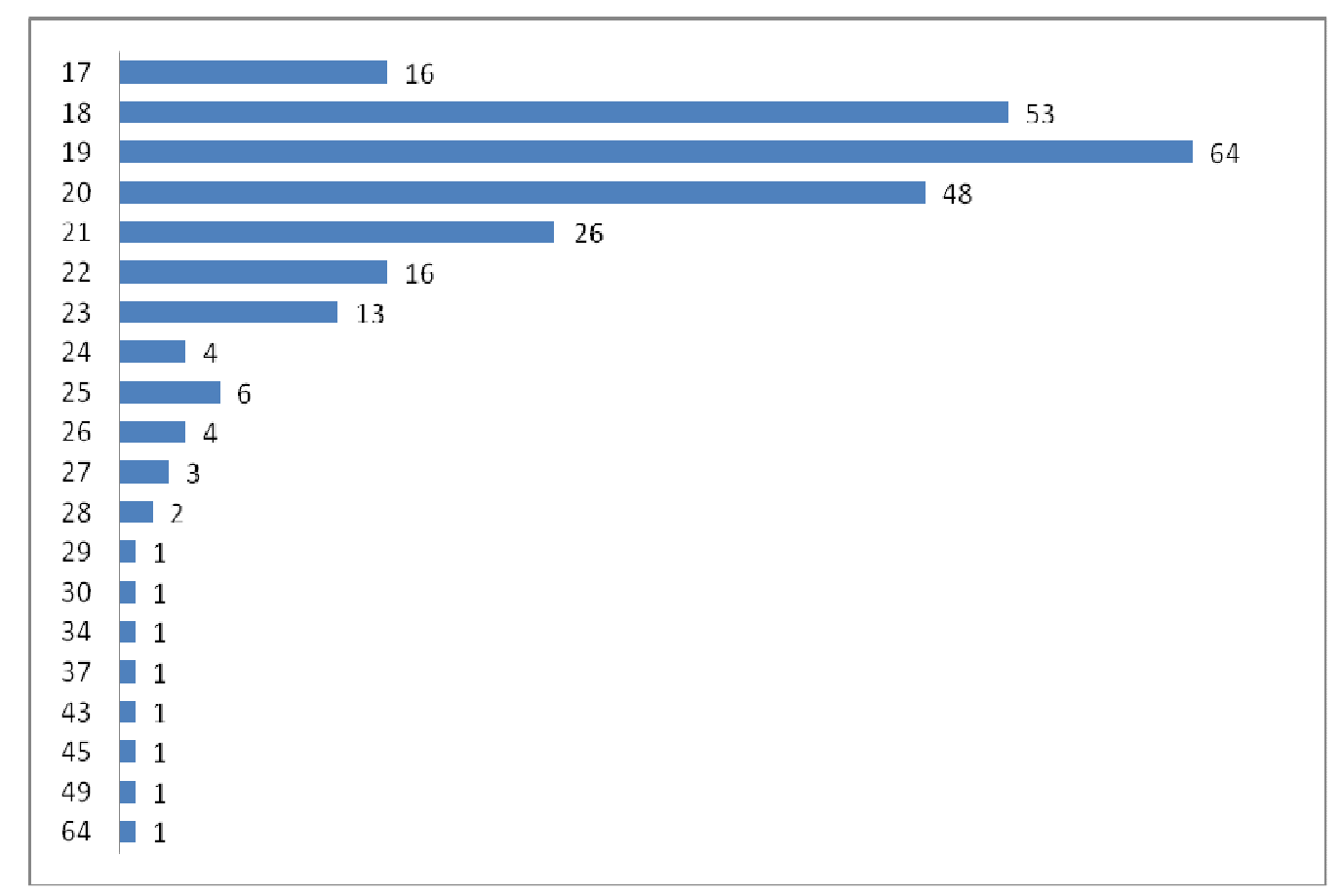

Gráfico 1: Histograma da composição etária da amostra.

Embora não diga respeito diretamente ao tema tratado neste artigo, o Gráfico 2, abaixo, traz as médias de leitura das obras da lista de vestibular, que, lembrando, era composta por 12 títulos. A média de leitura mais alta ficou no curso de Medicina, com 8,9, e a mais baixa, 4,6, foi na Publicidade. Atente-se que se trata de média aritmética. Dentro de cada curso houve distribuição desigual, com alguns casos de alunos que leram todas as obras e outros de estudantes que não fizeram qualquer leitura. Os números do Gráfico 2 dizem respeito à leitura integral, conforme declarada pelos respondentes. Comparando o Gráfico 2 com a Tabela 1, observa-se que os três cursos com maiores médias de leitura foram, na mesma ordem, as três maiores densidades de candidatos por vaga no vestibular 2011: Medicina, Direito e Psicologia. 


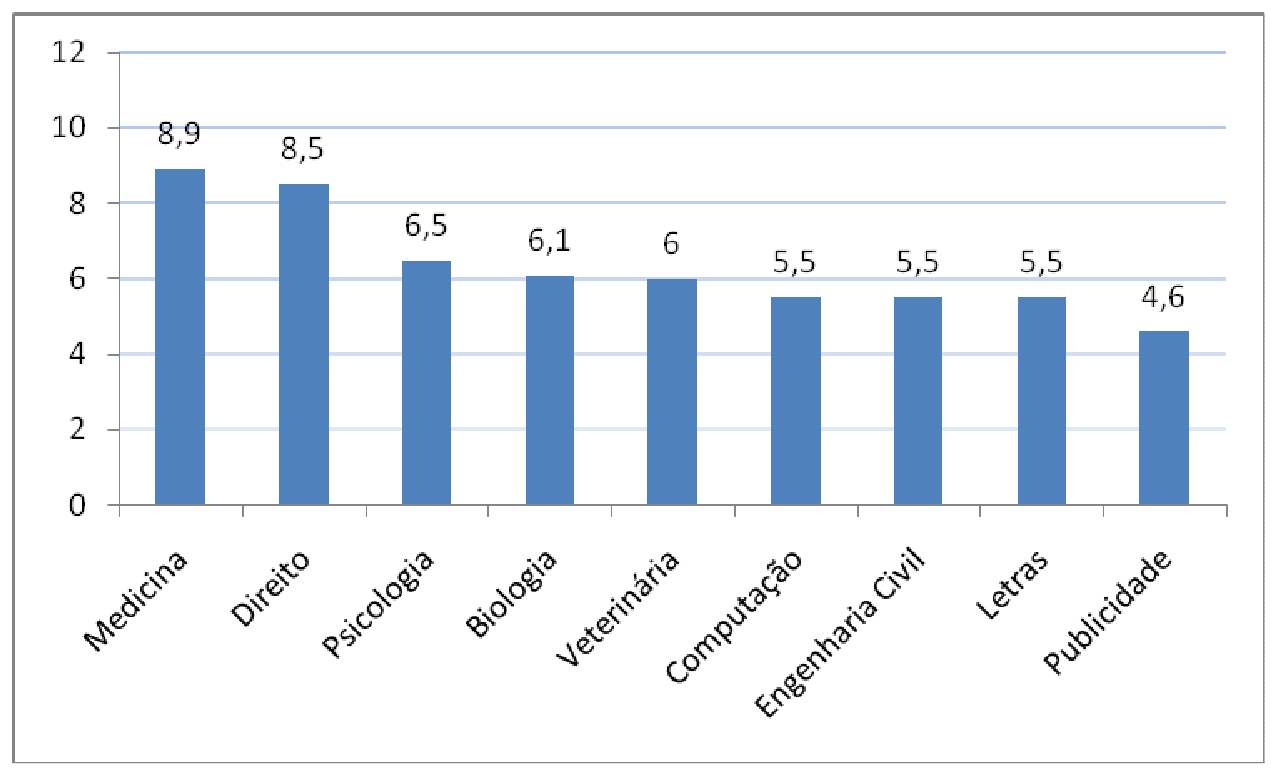

Gráfico 2. Médias de leitura da lista de 12 livros do vestibular

Mais relevante para o tema tratado neste artigo é a questão dos suportes de leitura. $\mathrm{O}$ formulário preenchido pelos respondentes solicitava que fossem marcadas as formas de apropriação das leituras da lista obrigatória. Deveriam ser assinaladas todas as categorias utilizadas, mesmo que a obra não tivesse sido lida na íntegra. As opções oferecidas eram as seguintes: "leu em livro impresso"; "leu em xerox ou apostila"; "leu no computador, netbook ou laptop"; "leu em celular, tablet ou leitor de e-book"; "leu resumo na Internet"; "leu resumo ou resenha em livro ou apostila"; "viu filme ou documentário"; "aprendeu em aula ou grupo de estudo"; "escutou audiolivro ou arquivo de áudio"; "outros (especificar)". Durante a tabulação, a alternativa "outros" foi desdobrada em duas categorias surgidas espontaneamente a partir das respostas, "peça de teatro" e "palestra". O ranking destes suportes está nos gráficos 3 e 4 . No Gráfico 3 é apresentada uma classificação em números absolutos. Ali, cada categoria assinalada por aluno para cada uma das 12 obras contava como um ponto. Já no Gráfico 4 é apresentado um ranking por aluno. Neste, cada respondente só contava uma vez para cada categoria marcada, independente de quantas obras tivesse marcado nela. No Gráfico 4, assim, o máximo valor atingido por coluna seria o do número de respondentes da amostra, 263, o que não chegou a acontecer. 


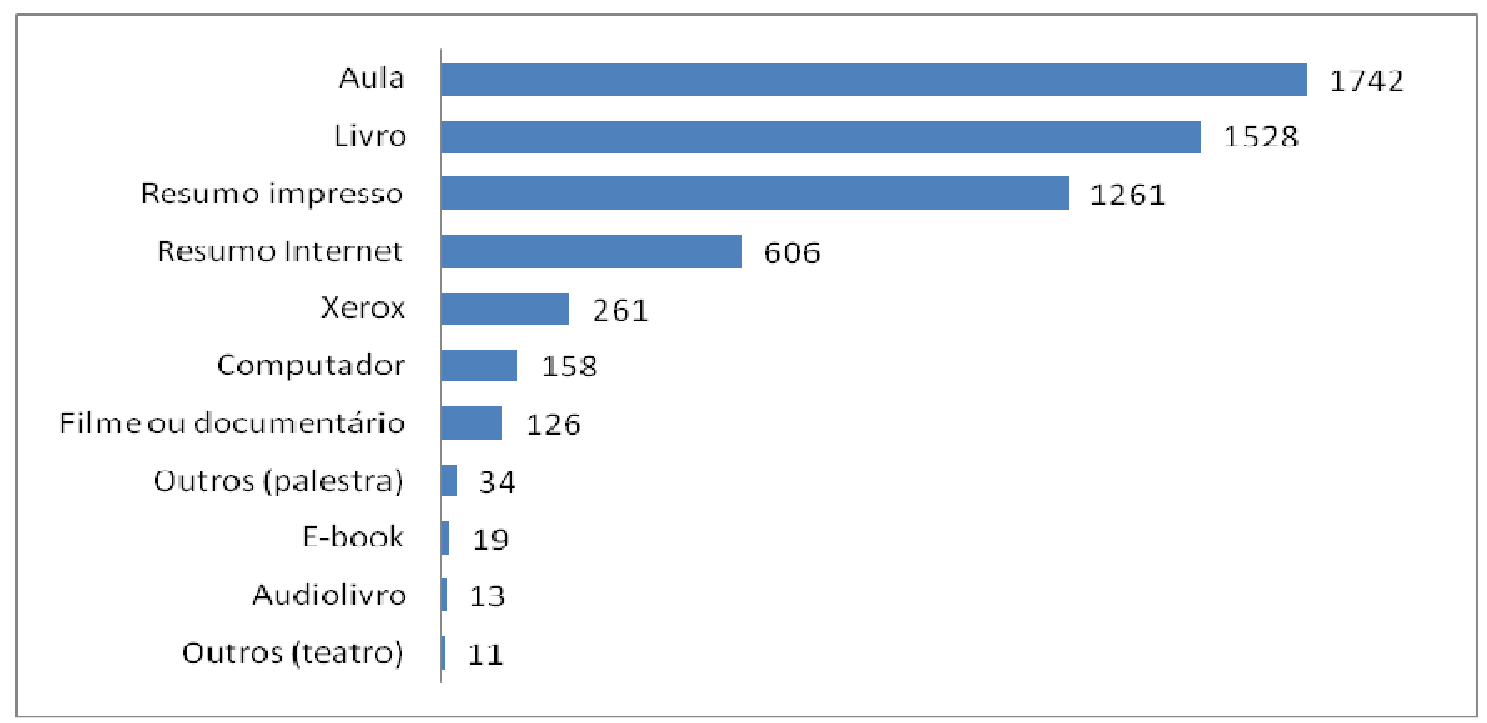

Gráfico 3: Ranking de suportes utilizados, dados absolutos.

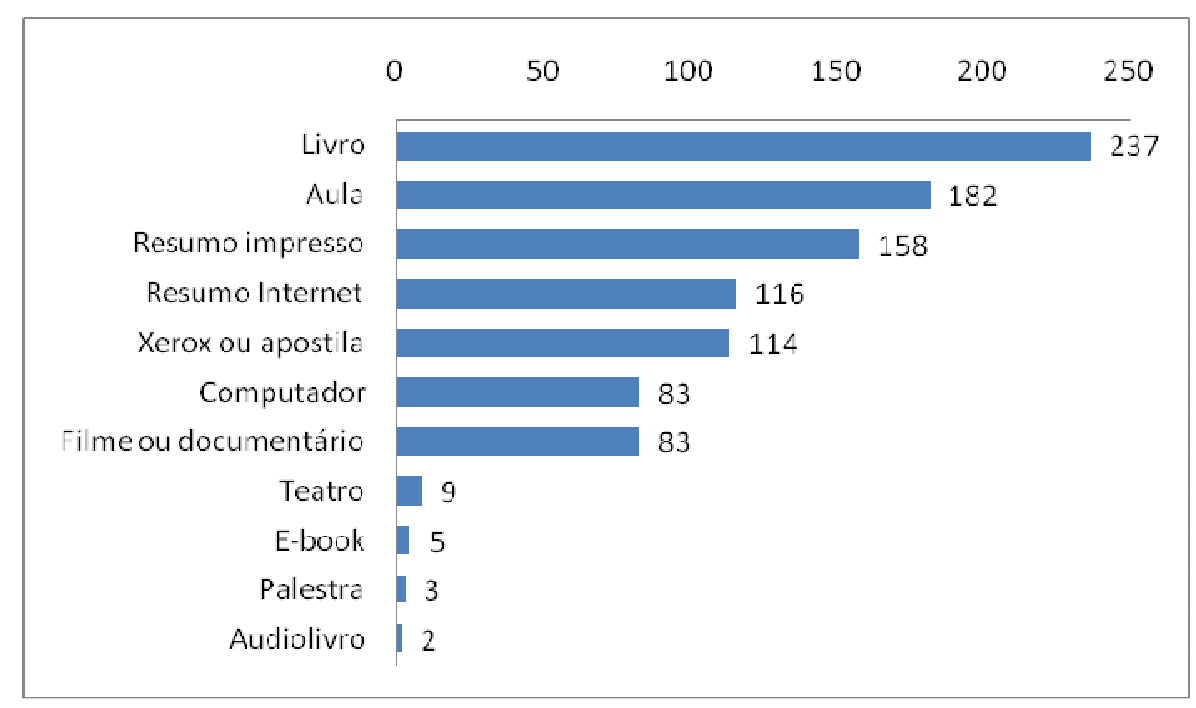

Gráfico 4: Ranking de suportes utilizados, dados por aluno.

Tanto no Gráfico 3 quanto no Gráfico 4 pode-se observar uma forte presença das marcações de "Aula", o que é uma decorrência direta das circunstâncias da amostra, já que se tratava de um grupo de estudantes com o objetivo de estudo específico do vestibular. O mesmo motivo poderia justificar a forte presença das categorias de resumo impresso e da Internet, assim como o pronunciado emprego de apostilas ou xeróx. 
São dados interessantes aqueles referentes à leitura em computador e as marcações de filme ou documentário. Pelo Gráfico 4, observa-se que a mesma quantidade de estudantes utilizou ambas as formas. Deve-se apontar que entre os 12 títulos da lista de leituras obrigatórias do vestibular havia apenas 3 com adaptações populares de cinema ou vídeo (Memórias Póstumas de Brás Cubas, O Primo Basílio e O Pagador de Promessas). Mesmo com esse universo reduzido, a quantidade de alunos que lançaram mão deste recurso audiovisual na preparação às provas foi equivalente àquela dos que realizaram leitura em computador. Podese especular que se houvesse mais títulos indicados com adaptações cinematográficas os números desta categoria seriam ainda maiores.

Não se deve esquecer que os dados do Gráfico 4 dizem respeito ao total de suportes assinalados pelos estudantes, o que significa que os 83 respondentes que marcaram ter tido contato com os títulos em filme não o fizeram necessariamente em exclusão das outras formas de contato com as obras. De fato, a sobreposição de modalidades foi bem notada ao longo do levantamento. O Gráfico 5 traz a frequência de superposição de categorias. Os dados contidos ali indicam quantas formas de contato com os títulos cada aluno utilizou. Nota-se concentração nas faixas de 3 a 5 . Um aluno na faixa dos 4, por exemplo, pode ter assinalado as opções "aula", "resumo Internet", "livro" e "computador", ou qualquer outra combinação com quatro categorias.

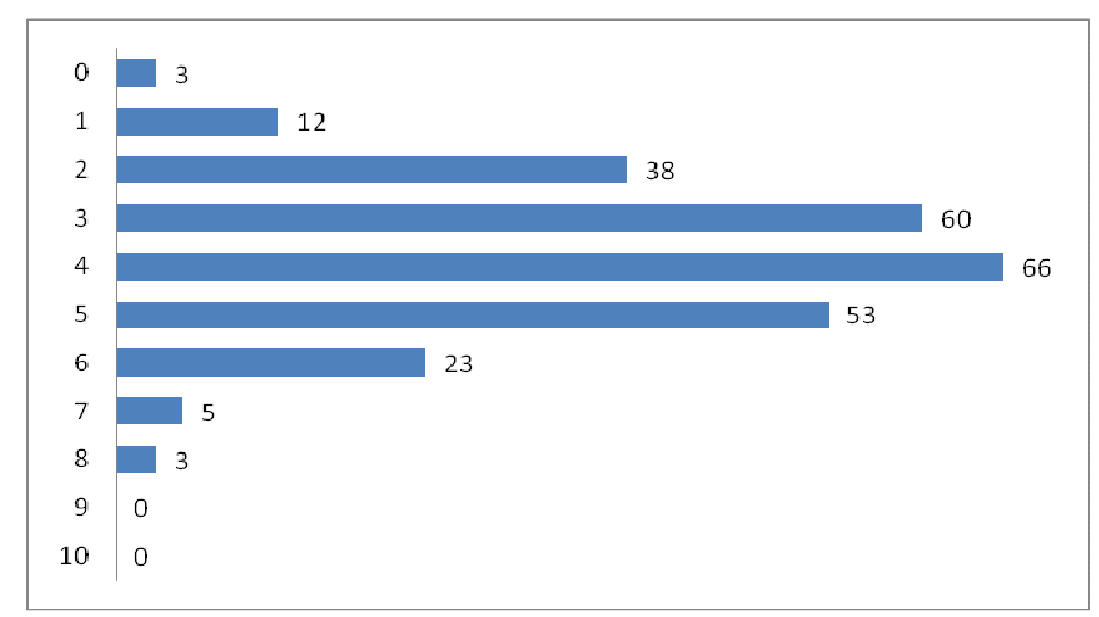


Gráfico 5: Ranking de suportes utilizados, dados por aluno.

Pode-se ilustrar a dimensão dos dados de sobreposição analisando-se individualmente os casos. A Tabela 3, abaixo, traz a ficha de preenchimento de um dos respondentes, uma estudante de Direito de 19 anos. A linha superior do quadro é composta pelas obras da lista de vestibular, pelo código alfabético que constava na Tabela 2. Pode-se observar na Tabela 3 que a aluna realizou bastante superposição de categorias. No gráfico 5 , ela pertence ao grupo de 23 respondentes que assinalaram 6 categorias (na Tabela 3 há sete linhas assinaladas, mas duas delas são o desdobramento da opção Outros, que no Gráfico 5 foi tabulada de forma unificada). Observa-se que para quase todas as obras a aluna marcou todas as formas de resumo (Internet e impresso), assim como livro impresso. Conjugou, ainda, outras mídias. Na obra C, em especial, assinalou ter tido contato em livro, computador, resumos, filme e, adicionalmente, palestra.

\begin{tabular}{|c|c|c|c|c|c|c|c|c|c|c|c|c|}
\hline & A & B & C & D & $\mathbf{E}$ & $\mathbf{F}$ & G & $\mathbf{H}$ & I & J & $\mathbf{K}$ & $\mathbf{L}$ \\
\hline Livro impresso & $\mathrm{x}$ & $x$ & $x$ & $x$ & $\mathrm{x}$ & $\mathrm{x}$ & $x$ & $x$ & $x$ & $X$ & $x$ & \\
\hline \multicolumn{13}{|l|}{ Xerox } \\
\hline Texto no computador & $\mathrm{x}$ & $\mathrm{x}$ & $x$ & & & & & & & & & $\mathrm{x}$ \\
\hline \multicolumn{13}{|c|}{ Leitor de e-book, celular ou tablet } \\
\hline resumo Internet & $\mathrm{x}$ & $x$ & $x$ & $\mathrm{x}$ & $x$ & $x$ & $\mathrm{x}$ & $x$ & $x$ & $X$ & $x$ & $x$ \\
\hline Resumo impresso & $\mathrm{x}$ & $\mathrm{x}$ & $x$ & $\mathrm{x}$ & $\mathrm{x}$ & $\mathrm{x}$ & $x$ & $x$ & $x$ & $x$ & $x$ & $x$ \\
\hline filme/documentário & & & $x$ & & & & & & & & & \\
\hline \multicolumn{13}{|l|}{ aula/grupo de estudo } \\
\hline \multicolumn{13}{|l|}{ audiolivro } \\
\hline outros: teatro & & & & & & & & & $x$ & & $\mathrm{x}$ & \\
\hline outros: palestra & $x$ & $x$ & $x$ & $x$ & $x$ & $x$ & $x$ & $x$ & & $\mathrm{X}$ & & $x$ \\
\hline
\end{tabular}

Tabela 3: Ficha de tabulação de uma das alunas pesquisadas. 
A estudante cuja ficha é mostrada na Tabela 3 foi também entrevistada por telefone, dentro de um procedimento metodológico de triangulação qualitativa da pesquisa. Ela disse que durante a preparação para as provas adotou como procedimento inicialmente ler as obras recomendadas em livro, depois comparando com filmes ou mesmo peças de teatro. Utilizou o texto eletrônico para facilitar a consulta a trechos específicos.

O caso da aluna não é estatisticamente representativo do grupo. Ela representa a minoria que assinalou uma quantidade maior de categorias. Ainda assim, embora constitua um caso extremo, ela foi escolhida para análise por concentrar a tendência de uso de múltiplas categorias que já podia ser observada mais discretamente em outras situações individuais e também no Gráfico 5.

Um outro resultado interessante do levantamento também envolve passagem entre formas de suporte. À parte a porção do questionário que indagava os estudantes a respeito do indicador primário (os livros da lista de leitura obrigatória do vestibular), o formulário também continha algumas perguntas sobre leitura em geral e formas de lazer. Um dos campos era "Quais dessas coisas você já fez?", cabeçaIho abaixo do qual constavam várias alternativas que podiam ser marcadas. Duas destas opções eram "Leu um livro porque ficou interessado depois de ter assistido a um filme baseado nele" e "Viu um filme porque era baseado em um livro que você leu". O objetivo destas questões era comparar a leitura de livros com as mídias audiovisuais. Uma das bases teóricas eram as análises de McLuhan (1972, p.311) e Birkerts (2006, p. 238) que contrapõem o meio impresso ao eletrônico em um caráter concorrencial. A tabulação destes resultados está na Tabela 4.

Os resultados mostrados na Tabela 4 podem ser considerados surpreendentes, tendo em vista que parecem indicar uma preferência dos respondentes pelas obras impressas. Uma quantidade maior de alunos assinalou ter visto um filme após ter lido um livro $(86,69 \%)$ do que ter assistido primeiro a um filme e depois 
lido o livro $(57,41 \%)$. Aproximadamente metade dos respondentes $(54,37 \%)$ indicou já ter feito ambas as coisas.

\begin{tabular}{|lrlrlrl|}
\hline & filme-livro & (\%) & livro-filme (\%) & Ambos (\%) \\
\hline MED & 18 & $56,25 \%$ & 29 & $90,63 \%$ & 18 & $56,25 \%$ \\
\hline DIR & 23 & $62,16 \%$ & 34 & $91,89 \%$ & 23 & $62,16 \%$ \\
\hline PSI & 13 & $61,90 \%$ & 19 & $90,48 \%$ & 12 & $57,14 \%$ \\
\hline BIO & 16 & $61,54 \%$ & 22 & $84,62 \%$ & 15 & $57,69 \%$ \\
\hline VET & 25 & $67,57 \%$ & 32 & $86,49 \%$ & 23 & $62,16 \%$ \\
\hline COMP & 17 & $58,62 \%$ & 25 & $86,21 \%$ & 15 & $51,72 \%$ \\
\hline ENG & 9 & $34,62 \%$ & 20 & $76,92 \%$ & 9 & $34,62 \%$ \\
\hline LET & 14 & $53,85 \%$ & 23 & $88,46 \%$ & 13 & $50,00 \%$ \\
\hline PP & 16 & $55,17 \%$ & 24 & $82,76 \%$ & 15 & $51,72 \%$ \\
\hline & & & & & & \\
\hline Total & $\mathbf{1 5 1}$ & $\mathbf{5 7 , 4 1 \%}$ & $\mathbf{2 2 8}$ & $\mathbf{8 6 , 6 9 \%}$ & $\mathbf{1 4 3}$ & $\mathbf{5 4 , 3 7 \%}$ \\
\hline
\end{tabular}

Filme-livro corresponde à opção "Leu um livro porque ficou interessado depois de ter assistido a um filme baseado nele" Livro-filme corresponde à opção "Viu um filme porque era baseado em um livro que você leu"

Tabela 4. Respostas sobre leitura de livro a partir de filme e audiência de filme a partir de livro.

Os resultados da Tabela 4 também foram triangulados através de entrevistas telefônicas. Uma estudante relatou efetivamente ter assistido a um filme porque era baseado em um livro que havia lido, mencionando inclusive o título ( $O$ Código da Vincl). Outra aluna que mencionou ter feito as duas coisas afirmou ter se interessado pela série de livros As Fronteiras do Universo após um contato inicial com a obra no filme A Bússola Dourada. Disse ter feito o mesmo com As Crônicas de Nárnia. Leu os títulos em meio eletrônico, através de um dispositivo móvel.

O questionário também continha um campo qualitativo, para ser preenchido com as palavras dos alunos. Era a última pergunta do instrumento de observação: "Independente de estudo, trabalho ou faculdade, o que você lê?" Pretendia-se com esta questão observar quais seriam as menções espontâneas. $O$ campo foi preenchido por 247 dos 263 respondentes, sendo que 221 (84,03\%) mencionaram livros. "Romances" receberam 82 menções (31,18\%); "literatura", 43 (16,35\%). Houve também variadas alusões a gêneros literários, como contos (17 estudantes), policial (16), fiç̧ão científica (14), aventura (13), fantasia (11), poesia (10), 
poemas (7). Também foram mencionados blogs (8 vezes), sites (6), quadrinhos (5), mangá (4) e fanfic (1).

Deve-se fazer a ressalva de que todos os dados apresentados nesta seção representam apenas indicativos, não índices estatísticos. Sem a pretensão de universalizar numericamente os resultados, buscava-se principalmente identificar relações, dentro da proposta de uma interpretação qualitativa. Neste sentido foram considerados interessantes os aspectos que indicam o fluxo de interesse de alguns estudantes que passa pela literatura atravessando mídias e suportes. É o que se infere das superposições de categorias de contato assinaladas pelos alunos na apropriação dos títulos da lista de leituras obrigatórias do vestibular, assim como pelas quantidades significativas de respondentes que mencionaram ter assistido a filmes após ter lido livros ou se interessado em livros após assistir aos filmes baseados neles. Somados, estes indicadores podem sinalizar a conveniência de investigações futuras que busquem compreender como o envolvimento de públicos similares ao pesquisado com a literatura pode passar, em maior ou menor grau, pela multiplicidade de suportes.

\section{Considerações finais}

A operação de cotejo de dados empíricos com as projeções teóricas sempre deve ser efetuada com cautela. Trabalhos de observação de campo costumam ser planejados a partir de um construto teórico ou modelização inicial, comparando-se depois os resultados com as expectativas, dentro do grande processo científico de refinamento de modelos e teorias. Há, no caminho, diversas considerações e fatores limitantes, como a inevitável simplificação de conceitos quando da apropriação com vistas à elaboração das ferramentas de pesquisa e, ainda, as limitações epistemológicas e metodológicas inerentes ao tipo de observação ou ao corpus escolhidos.

No caso da pesquisa apresentada na seção anterior, trabalhou-se com um corpus muito específico, de estudantes universitários aprovados em um vestibular fede- 
ral. Isso circunscreve, talvez acentuadamente, muitos dos resultados à porção do público em geral que tenha necessidades ou realidades similares. Além desta singularidade do corpus, também há as considerações epistemológicas, como a inevitável distorção produzida por uma amostragem reduzida e a própria filtragem representada pela ferramenta de observação, no caso o questionário. É necessário ter em mente todas essas ressalvas antes de retornar às fontes teóricas para a operação de cotejo.

O aspecto mais inesperado da pesquisa, no que se refere aos postulados teóricos mencionados na seção 1 deste artigo, é constituído pelo caráter de complementaridade entre suportes de apropriação de conteúdo. O uso múltiplo de categorias de contato com obras literárias, como no caso da estudante detalhada na Tabela 3 , sugere um panorama consideravelmente mais complexo do que uma mera oposição entre tecnologia tipográfica e eletrônica, como poderia sugerir uma primeira apropriação das observações de Marshall McLuhan (1972, p.311) ou Sven Birkerts (2006, p. 238). Naturalmente, isso não significa a inaplicabilidade dos autores em questão, mas indica que a problematização que fazem não pode ser simplificada facilmente. Os postulados apresentados por esta linha teórica podem ter aplicação em escalas de tempo maiores e em estratos culturais mais amplos do que o corpus tratado pela pesquisa inicial apresentada na seção 2. Ainda assim, é interessante como as alusões espontâneas dos estudantes, tanto quanto as induzidas contidas pelo questionário, apontaram uma complementaridade de mídias mais do que uma oposição ou concorrência, pelo menos no que se refere ao consumo de gêneros literários.

Metodologicamente não é possível extrair conclusões da observação que permitam questionar os postulados teóricos. Tomado como indicativo inicial, contudo, este estudo exploratório poderia ajudar a demarcar um campo viável de investigação para o futuro. Poderia ser útil buscar compreender sem necessariamente adotar um viés teórico valorativo um eventual fenômeno de multiplicidade de suportes na fruição de obras literárias. São avenidas possíveis de pesquisa, neste caso, a consolidação dos resultados em novos estudos e o aprofundamento da consulta 
às fontes teóricas, em direção a conceitos que possam enriquecer a modelização dos construtos à luz da riqueza e complexidade da observação empírica. Por enquanto, resta considerar que a questão do contato dos jovens com a literatura, passando pela clássica forma impressa do livro ou em paralelo aos meios audiovisuais e eletrônicos, pode conter em si mesma uma profundidade maior do que se poderia inicialmente estimar.

\section{ANALYZING INDICATORS ON THE RECEPTION OF LITERATURE WITHIN A MULTIPLE MEDIA ENVIRONMENT}

ABSTRACT: Starting from observations of authors such as Marshall McLuhan and Sven Birkerts, a survey sought to observe the ways by wich a group of students took contact with literary material, seeking eventual cases of replacement of reading by audiovisual media. The results showed that in place of opposition or competition there was a complementarity between the uses of the multiple media involved. The primary indicator adopted in the survey was the mandatory reading list for the literature test of vestibular of the Federal University of Rio Grande do Sul. It was observed that several students employed multiple forms of appropriation of the contents of the literary works, and were even observed study strategies that consciously alternated medias in order to maximize the results.

KEYWORDS: Reading, Electronic book, Future of the book, Multiple media.

\section{REFERÊNCIAS}

BIRKERTS, Sven. The Gutenberg Elegies: The fate of reading in an electronic age. New York: Faber and Faber, 2006.

MCLUHAN, Marshall. A Galáxia de Gutenberg: a formação do homem tipográfico. São Paulo: Editora Nacional/Editora da USP, 1972.

SILVA, Juremir Machado da. A sociedade midíocre: passagem ao hiperespetacular: o fim do direito autoral, do livro e da escrita. Porto Alegre: Sulina, 2012.

THOMPSON, John B. Books in the digital age. Cambridge: Polity, 2008.

ULIN, David L. The lost art of reading: why books matter in a distracted time. Seattle: Sasquatch Books, 2010.

Texto recebido em 28/10/2013.

Texto aprovado em 29/11/2013. 